\title{
Comparative Assessment of Pesticide Exposures in Domestic Dogs and Their Owners Using Silicone Passive Samplers and Biomonitoring
}

Catherine F. Wise ${ }^{\dagger}$, Stephanie C. Hammel ${ }^{\dagger}$, Nicholas Herkert ${ }^{\dagger}$, Maria Ospina ${ }^{\S}$, Antonia M. Calafat $\$$, Matthew Breen ${ }^{\|, \perp, \#,+,}$ and Heather M. Stapleton $*,+, \neq$

$\dagger$ Nicholas School of the Environment, Duke University, Durham, North Carolina 27708, USA.

$¥$ Duke Cancer Institute, Durham, North Carolina, USA.

$\S$ Division of Laboratory Sciences, National Center for Environmental Health, Centers for

Disease Control and Prevention, 4770 Buford Hwy, MSS103-2, Atlanta, Georgia 30341, USA.

" Department of Molecular Biomedical Sciences, College of Veterinary Medicine, North Carolina State University, 1060 William Moore Drive, Raleigh, North Carolina 27607, USA.

${ }^{\perp}$ Comparative Medicine Institute, North Carolina State University, Raleigh, North Carolina 27607, USA.

\# Center for Human Health and the Environment, North Carolina State University, Raleigh, North Carolina 27607, USA.

${ }^{\circ}$ Present Address: The National Research Centre for the Working Environment, Copenhagen, Denmark

*Heather Stapleton, $\mathrm{PhD}$

Ronie-Richele Garcia-Johnson Distinguished Professor

Nicholas School of the Environment

Duke University

9 Circuit Drive, Box 90328

Durham, NC 27708

Phone: 919.613 .8717

Fax: 919.684 .8741

Email: heather.stapleton@duke.edu

Lab site: https://sites.nicholas.duke.edu/stapletonlab/ 


\section{Contents}

Table S1. Urine pesticide biomarker analyte summary $(\mu \mathrm{g} / \mathrm{L})$.

Table S2. Information collected on the reported flea and tick products used by study participants on the participating dog. Also included are the corresponding specific gravity corrected urinary metabolite

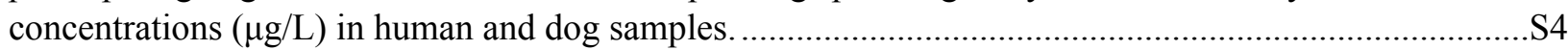

Table S3. Matrix spike recoveries for pesticide extraction and analysis from the wristband matrix..........S5

Figure S1. Reported use of pesticide containing flea and tick preventatives. ..........................................S6

Figure S2. A comparison of the neonicotinoid pesticide urinary biomarker $95^{\text {th }}$ percentile concentrations for chemicals with a low detection frequency. Absence of a bar indicates the $95^{\text {th }}$ percentile for that set of samples was $<$ LOD.

Figure S3. A comparison of pesticide biomarker concentrations in urine samples from humans and dogs.

Supplemental Information References: 
Table S1. Urine pesticide biomarker analyte summary $(\mu \mathrm{g} / \mathrm{L})$.

\begin{tabular}{|c|c|c|c|c|c|c|}
\hline Biomarker Name & $\begin{array}{l}\text { Biomarker } \\
\text { Abbreviation }\end{array}$ & Parent chemical & Chemical class & $\begin{array}{l}\text { Analytical } \\
\text { LOD*}^{*}\end{array}$ & $\begin{array}{l}\text { Adult } \\
\text { Reference } \\
\text { range }\end{array}$ & $\begin{array}{l}\text { Literature } \\
\text { references }\end{array}$ \\
\hline 3-(diethylcarbamoyl)benzoic acid & DCBA & $\begin{array}{l}\text { N,N-diethyl-meta-toluamide } \\
\text { (DEET) }\end{array}$ & Insect repellent & 0.2 & 2.93-145 & 3 \\
\hline 3-(ethylcarbamoyl)benzoic acid & ECBA & $\begin{array}{l}\text { N,N-diethyl-meta-toluamide } \\
\text { (DEET) }\end{array}$ & Insect repellent & 0.2 & $1.08-50.5$ & 3 \\
\hline Imidacloprid & IMI & Imidacloprid & Neonicotinoid & 0.4 & $<$ LOD & 2,3 \\
\hline 5-Hydroxy imidacloprid & 5-OH-IMI & Imidacloprid & Neonicotinoid & 0.4 & $<$ LOD-1.38 & 2,3 \\
\hline Thiacloprid & THIAC & Thiacloprid & Neonicotinoid & 0.03 & $<\mathrm{LOD}$ & 2,3 \\
\hline Clothianidin & CLOTH & Clothianidin, Thiamethoxam & Neonicotinoid & 0.2 & $<$ LOD-0.393 & 2,3 \\
\hline Acetamiprid & ACET & Acetamiprid & Neonicotinoid & 0.3 & $<\mathrm{LOD}$ & 2,3 \\
\hline Acetamiprid-N-desmethyl & ACET-Ndes & Acetamiprid & Neonicotinoid & 0.2 & $<$ LOD-1.27 & 2,3 \\
\hline $\begin{array}{l}\text { 2-isopropyl-4-methyl-6- } \\
\text { hydroxypyrimidine }\end{array}$ & IMPY & Diazinon & Organophosphate & 0.1 & $<$ LOD-0.496† & 3 \\
\hline 3,5,6-Trichloro-2-pyridinol & TCPY & Chlorpyrifos, Chlorpyrifos-methyl & Organophosphate & 0.1 & $0.97-4.18 \ddagger$ & 1 \\
\hline para-Nitrophenol & PNP & $\begin{array}{l}\text { Parathion, methyl parathion, ethyl } \\
\text { parathion, nitrobenzene, O-ethyl- } \\
\text { O-(4-nitrophenyl) } \\
\text { phenylphosphonothioate, }\end{array}$ & Organophosphate & 0.1 & $0.572-3.21 \dagger$ & 3 \\
\hline 2,4-Dichlorophenoxyacetic acid & 2,4-D & $\begin{array}{l}\text { 2,4-Dichlorophenoxyacetic acid } \\
\text { (and it's esters) }\end{array}$ & Phenoxy acid & 0.15 & $0.272-1.32 \dagger$ & 3 \\
\hline 3-phenoxybenzoic acid & 3-PBA & $\begin{array}{l}\text { Cyhalothrin, Cypermethrin, } \\
\text { Deltamethrin, Fenpropathrin, } \\
\text { Permethrin, Tralomethrin }\end{array}$ & Pyrethroid & 0.1 & $0.62-7.36 \dagger$ & 3 \\
\hline 4-fluoro-3-phenoxybenzoic acid & 4-F-3-PBA & Cyfluthrin, Flumethrin & Pyrethroid & 0.1 & $<$ LOD-0.177† & 3 \\
\hline $\begin{array}{l}\text { trans-3-(2,2-Dichlorovinyl)-2,2- } \\
\text { dimethylcyclopropane carboxylic } \\
\text { acid }\end{array}$ & trans-DCCA & $\begin{array}{l}\text { Permethrin; Cypermethrin; } \\
\text { Cyfluthrin }\end{array}$ & Pyrethroid & 0.6 & $<$ LOD-6.3† & 3 \\
\hline
\end{tabular}

*Results near the limit of detection (LOD) are subject to greater uncertainty. The LOD $=3 *$ SD (the standard deviation of the concentration derived from the measurement process as the concentration approaches zero). Limit of detection (LOD) and reference ranges are in $\mu \mathrm{g} / \mathrm{L}$. Reference ranges are limited to the $50^{\text {th }}$ and $95^{\text {th }}$ percentile intervals for the U.S. population 20 years of age and older from NHANES 2015-2016 unless otherwise noted. $\neq$ Values limited to the 50th to the 95th percentile intervals for the U.S. population ages 20-59 from NHANES 2009-2010. + Values limited to the 50th to the 95th percentile intervals for the U.S. population 20 years of age and older from NHANES 2013-2014. 
Table S2. Information collected on flea and tick products used on the participating dog by study participants. Also included are the corresponding specific gravity corrected urinary metabolite concentrations $(\mu \mathrm{g} / \mathrm{L})$ in human and dog samples.

\begin{tabular}{|c|c|c|c|c|c|c|c|c|}
\hline ID \# & Imidacloprid & 5-OH-IMI human & IMI human & 5-OH-IMI dog & IMI dog & Flumethrin & 4-F-3-PBA human & 4-F-3-PBA dog \\
\hline CEA0001 & No & $<\mathrm{LOD}$ & $<$ LOD & 13.09 & 0.77 & No & $<\mathrm{LOD}$ & $<\mathrm{LOD}$ \\
\hline CEA0002 & No & $\ddagger$ & 0.59 & $<$ LOD & $<\mathrm{LOD}$ & No & $<\mathrm{LOD}$ & $<$ LOD \\
\hline CEA0003 & No & $<$ LOD & 0.55 & 1.46 & $<$ LOD & No & 1.25 & $<$ LOD \\
\hline CEA0004 & No & $\ddagger$ & 0.74 & $<L O D$ & $<\mathrm{LOD}$ & No & $<\mathrm{LOD}$ & $<L O D$ \\
\hline CEA0005 & Yes & $\ddagger$ & 1.50 & 79.10 & 9.26 & Yes & 0.38 & 0.55 \\
\hline CEA0006 & No & $<L O D$ & 0.49 & $<\mathrm{LOD}$ & $<L O D$ & No & $<\mathrm{LOD}$ & $<\mathrm{LOD}$ \\
\hline CEA0007 & Yes & $\ddagger$ & $\ddagger$ & 782.27 & 158.34 & Yes & 0.76 & 1.33 \\
\hline CEA0008 & Yes & 23.85 & $\ddagger$ & 95.16 & 23.33 & Yes & 0.62 & 0.24 \\
\hline CEA0009 & Yes & $\ddagger$ & $\ddagger$ & 215.40 & 29.83 & Yes & 0.33 & 1.17 \\
\hline CEA0010 & No & $\ddagger$ & 0.50 & 1.06 & $\ddagger$ & No & $<\mathrm{LOD}$ & $<L O D$ \\
\hline CEA0011 & No & $<L O D$ & $<$ LOD & $<$ LOD & $\ddagger$ & No & $<$ LOD & $<$ LOD \\
\hline CEA0012 & No & 1.18 & 0.92 & $<L O D$ & $<L O D$ & No & $<\mathrm{LOD}$ & $<L O D$ \\
\hline CEA0013 & Yes & 1.70 & $<L O D$ & $\ddagger$ & $<L O D$ & Yes & 0.23 & $<L O D$ \\
\hline CEA0014 & No & $<\mathrm{LOD}$ & $<\mathrm{LOD}$ & $<$ LOD & $<\mathrm{LOD}$ & No & $<\mathrm{LOD}$ & $<\mathrm{LOD}$ \\
\hline CEA0015 & No & $\ddagger$ & 0.49 & $\ddagger$ & 0.41 & No & $<L O D$ & $<\mathrm{LOD}$ \\
\hline CEA0016 & Historical & $\ddagger$ & $<\mathrm{LOD}$ & 40.71 & $\ddagger$ & No & $<$ LOD & $<\mathrm{LOD}$ \\
\hline CEA0017 & No & $<\mathrm{LOD}$ & $<L O D$ & $<\mathrm{LOD}$ & $<\mathrm{LOD}$ & No & $<\mathrm{LOD}$ & $<\mathrm{LOD}$ \\
\hline CEA0018 & No & $<\mathrm{LOD}$ & $<L O D$ & $<L O D$ & $<L O D$ & No & $<$ LOD & $<\mathrm{LOD}$ \\
\hline CEA0019 & No & $<L O D$ & $<L O D$ & $\ddagger$ & $\ddagger$ & No & $<\mathrm{LOD}$ & $<L O D$ \\
\hline CEA0020 & Yes & $\ddagger$ & $<L O D$ & 24.42 & 3.89 & No & $<$ LOD & $<\mathrm{LOD}$ \\
\hline CEA0021 & No & $\ddagger$ & 0.70 & $<\mathrm{LOD}$ & $<\mathrm{LOD}$ & No & $<$ LOD & $<L O D$ \\
\hline CEA0022 & No & $\ddagger$ & $<L O D$ & $<L O D$ & $<L O D$ & No & $<L O D$ & $<L O D$ \\
\hline CEA0023 & No & $\ddagger$ & $\ddagger$ & 147.65 & 25.17 & No & $<\mathrm{LOD}$ & $<\mathrm{LOD}$ \\
\hline CEA0025 & No & 1.03 & $<L O D$ & 7.96 & $\ddagger$ & No & 0.26 & $<\mathrm{LOD}$ \\
\hline CEA0026 & Yes & $\ddagger$ & $\ddagger$ & $\ddagger$ & 7.47 & Yes & 0.16 & 0.22 \\
\hline CEA0027 & No & $<L O D$ & $<\mathrm{LOD}$ & $<L O D$ & $<L O D$ & No & $<$ LOD & $<\mathrm{LOD}$ \\
\hline CEA0028 & No & $<\mathrm{LOD}$ & 0.42 & $<$ LOD & $<\mathrm{LOD}$ & No & $<\mathrm{LOD}$ & $<\mathrm{LOD}$ \\
\hline CEA0029 & No & $\ddagger$ & 0.53 & 9.23 & $\neq$ & No & 0.49 & $<L O D$ \\
\hline CEA0030 & No & 2.66 & $<$ LOD & $<L O D$ & $<\mathrm{LOD}$ & No & $<L O D$ & $<L O D$ \\
\hline CEA0031 & Historical & 11.97 & $\ddagger$ & 150.11 & 21.44 & Historical & 0.23 & $<L O D$ \\
\hline
\end{tabular}

Questionnaire responses indicated each participant did (Yes) or did not (No) report use of flea and tick products containing specific pesticides (imidacloprid/flumethrin). "Historical" indicates that the dog has been treated with a flea and tick product with that particular active ingredient within the past year but was not using that product during the time of the study period. Concentrations of associated urinary biomarkers, 5-OH-IMI and IMI for imidacloprid and 4-F-3-PBA for flumethrin, were measured in human and dog urine. $\ddagger$ Some samples had mass spectrometry interferences that prevented accurate quantification of some biomarkers, those samples were excluded from statistical analysis. $<$ LOD means that concentrations were below the limit of detection. 
Table S3: Matrix spike recoveries for pesticides extracted from wristbands. Recoveries represent the average recovery from three replicates. Each replicate involved spiking anywhere from $50-$ $250 \mathrm{ng}$ onto a 1-gram piece of silicone.

\begin{tabular}{l|lc} 
COMPOUND & \multicolumn{2}{c}{$\begin{array}{c}\text { \% RECOVERY } \\
\text { OF MATRIX } \\
\text { SPIKE }\end{array}$} \\
\hline $\begin{array}{l}\text { N,N-DIETHYL-META- } \\
\text { TOLUAMIDE (DEET) } \\
\text { LINDANE }\end{array}$ & $134-62-3$ & $104 \%$ \\
CHLORPYRIFOS & $58-89-9$ & $84 \%$ \\
FIPRONIL & $2921-88-2$ & $101 \%$ \\
TRANS-CHLORDANE & $120068-37-3$ & $91 \%$ \\
CIS-CHLORDANE & $5103-74-2$ & $99 \%$ \\
CIS-PERMETHRIN & $5103-71-9$ & $99 \%$ \\
TRANS-PERMETHRIN & $61949-76-6$ & $105 \%$ \\
CYPERMETHRIN & $61949-77-7$ & $112 \%$ \\
AZOXYSTROBIN & $52315-07-8$ & $89 \%$ \\
& $131860-33-8$ & $115 \%$
\end{tabular}



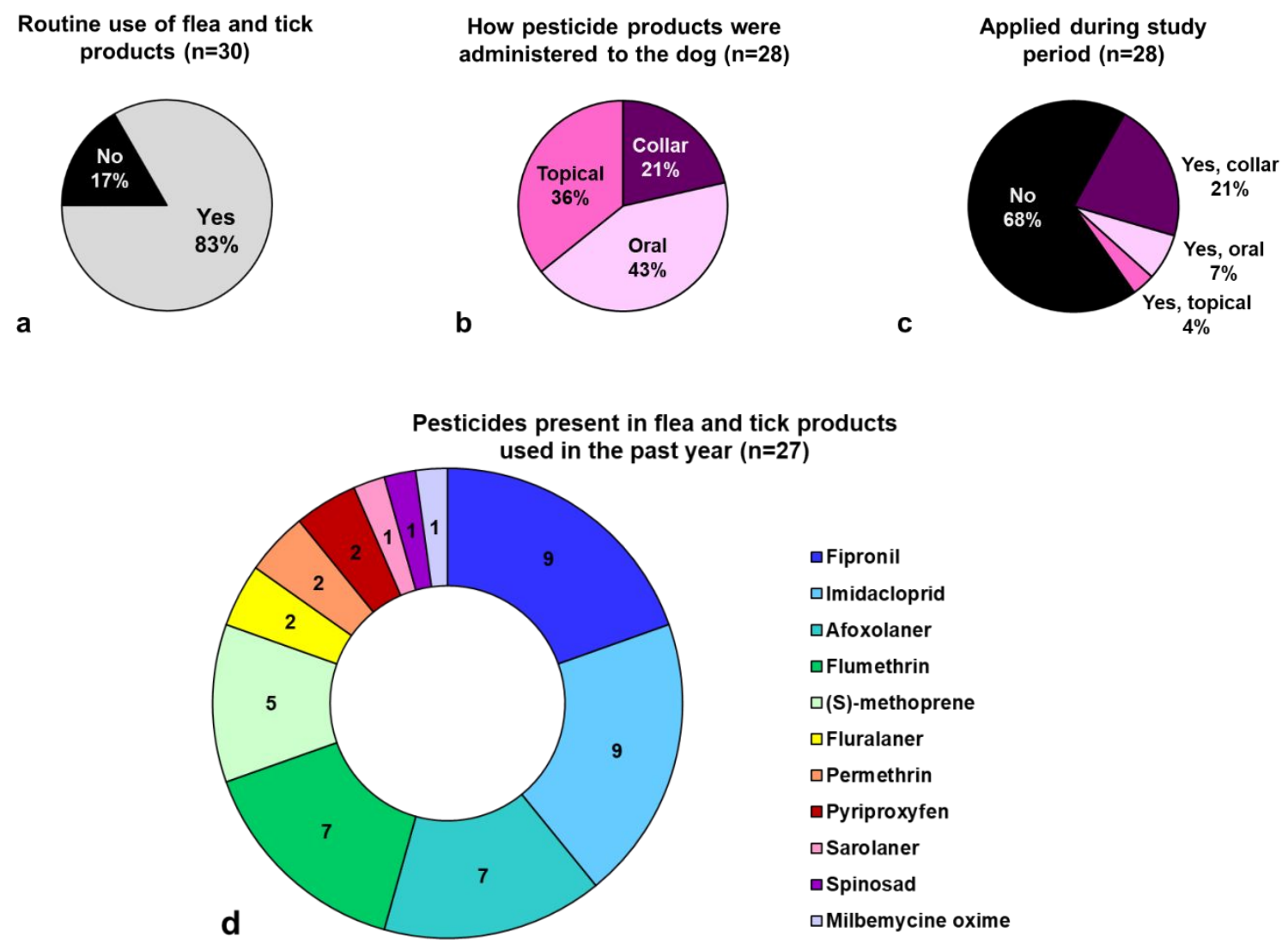

Figure S1. Reported use of pesticide containing flea and tick preventatives.

A majority of study participants routinely use pesticide containing flea and tick products on their $\operatorname{dog}(\mathrm{a})$. Two owners reported they did not use any flea and tick preventatives on their dog within the past year. Participants reported how the most recent application of the pesticide products were administered (b) and whether the application occurring during the study period (c). In total, owners reported 11 different pesticides listed as active ingredients in the flea and tick preventatives used for their dogs during the previous year (d). One owner did not indicate which product was used. Numbers reported in the chart are total number of dogs exposed to each pesticide. 


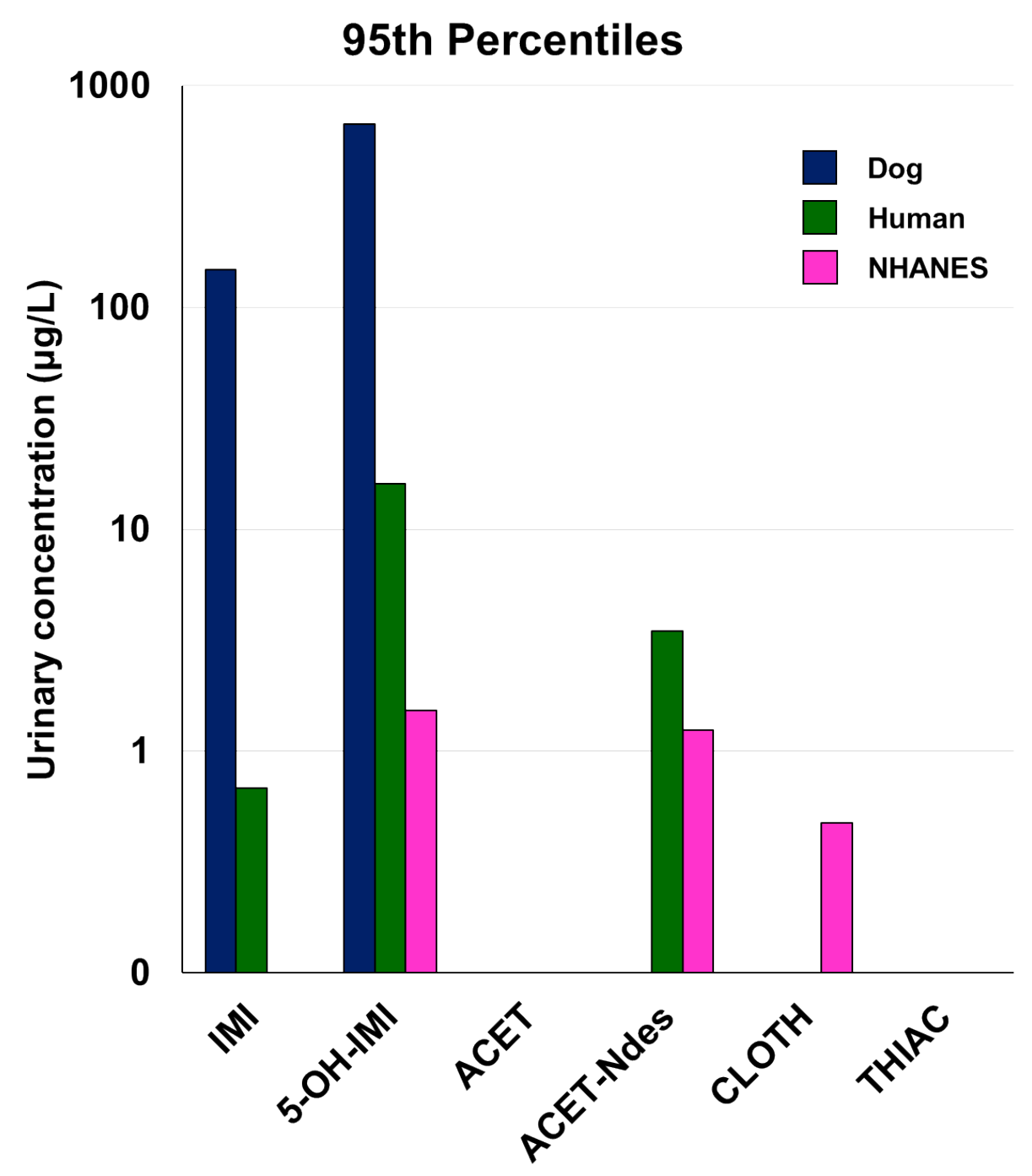

Figure S2. A comparison of the neonicotinoid pesticide urinary biomarker $95^{\text {th }}$ percentile concentrations for chemicals with a low detection frequency. Absence of a bar indicates the $95^{\text {th }}$ percentile for that set of samples was $<$ LOD. 


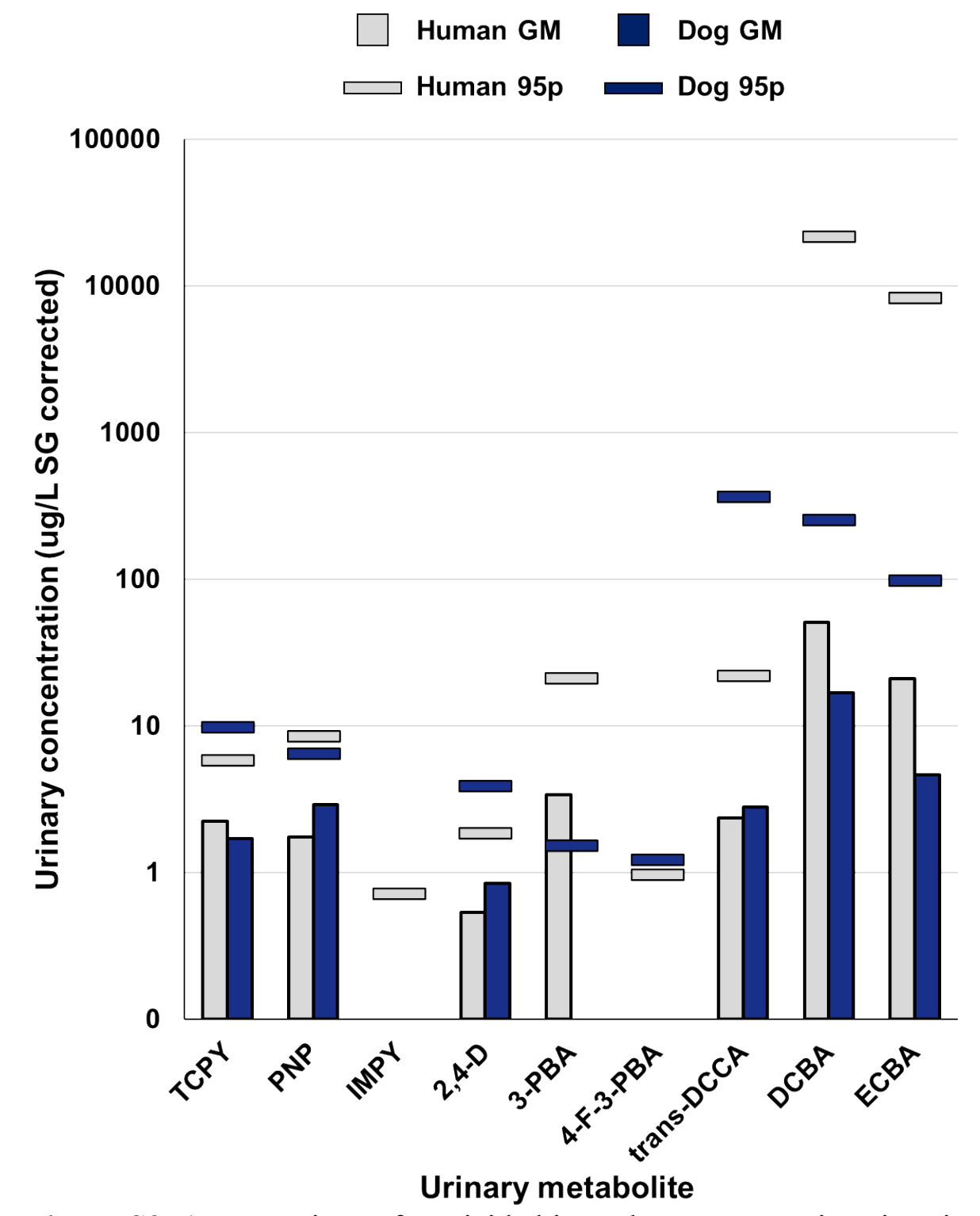

Figure S3. A comparison of pesticide biomarker concentrations in urine samples from humans and dogs. Comparisons are shown for the geometric mean (GM) and $95^{\text {th }}$ percentiles $(95 \mathrm{p})$ based on SG corrected concentrations of frequently detected metabolites measured in human and dog urine in our study. Comparisons were not included for analytes with a high proportion of samples with concentrations $<$ LOD. IMPY was not detected in any dog urine samples. 


\section{Supplemental Information References:}

1. Fourth National Report on human Exposure to Environmental Chemicals, Updated Tables, Volume One, March 2018, DLS, NCEH, CDC,

https://www.cdc.gov/exposurereport/pdf/FourthReport_UpdatedTables_Volume1_Mar2018.pdf

2. Ospina, M.; Wong, L.Y.; Baker, S.E.; Bishop Serafim, A.; Morales-Agudelo, P. and Calafat, A.M. Exposure to Neonicotinoid Insecticides in the U.S. General Population: Data from the 2015-2016 National Health and Nutrition Examination Survey. Env. Res. 2019, 176, 108555; DOI 10.1016/j.envres.2019.108555.

3. Fourth National Report on Human Exposure to Environmental Chemicals, Updated Tables, March 2021, DLS, NCEH, CDC. https://www.cdc.gov/exposurereport/ 